\title{
ENSINO MÉDIO INTEGRADO NO IFSULDEMINAS: CAMINHOS E DESCOMPASSOS
}

\author{
Heloisa Helena Coutinho PEREIRA ${ }^{1}$ \\ Luana Costa ALMEIDA ${ }^{2}$
}

\begin{abstract}
Resumo
O artigo objetiva analisar os caminhos e conquistas, desafios e descompassos na busca pela implementação da proposta de ensino médio integrado no IFSULDEMINAS. Para tanto, dentro da perspectiva qualitativa de pesquisa, a investigação teve como principais instrumentos de coleta de dados a análise documental e a entrevista semiestruturada. Documentalmente, utilizamos especialmente os Planos de Desenvolvimento Institucional (2009-2018) e os Projetos Pedagógicos dos Cursos (2012-2017). Nas entrevistas (2016-2017), contemplamos um representante da gestão, condutor das políticas de ensino, e quatro coordenadores de curso, indicados por melhor consolidarem a proposta de formação integrada. Os dados foram analisados na perspectiva da análise de conteúdo, em que selecionamos as unidades de análise e identificamos seus núcleos de conteúdo para a organização das temáticas analíticas do estudo. Os dados revelam uma tentativa importante de efetivação da formação integral, embora haja certo descompasso entre algumas concepções postas pela literatura, pelos documentos norteadores e anunciadas pelos coordenadores.
\end{abstract}

Palavras-chave: Educação Integral. Ensino médio integrado. Institutos Federais.

\footnotetext{
${ }^{1}$ Mestra em Educação. Pró-Reitoria de Ensino. Instituto Federal de Educação, Ciência e Tecnologia do Sul de Minas Gerais. Pouso Alegre, MG, Brasil. ORCID: 0000-0002-4678-9065.

E-mail: helohcoutinho@gmail.com.

${ }^{2}$ Doutora em Educação. Departamento de Teorias e Práticas Pedagógicas. Universidade Federal de São Carlos. São Carlos, SP, Brasil. ORCID: 0000-0003-0664-6796.

E-mail: luanaca@ufscar.br.
} 


\title{
INTEGRATED HIGH SCHOOL AT IFSULDEMINAS: PATHS AND MISMATCHES
}

\author{
Heloisa Helena Coutinho PEREIRA \\ Luana Costa ALMEIDA
}

\begin{abstract}
The article aims to analyze the paths and achievements, challenges and mismatches in the search for the implementation of the proposal of integrated high school at IFSULDEMINAS. For this, within a qualitative research perspective, the investigation had as main instruments of data collection the documental analysis and semi-structured interviews. Documentarily, we used especially the Planos de Desenvolvimento Institucional (Institutional Development Plans) (2009-2018) and the Projetos Pedagógicos dos Cursos (Pedagogical Projects of the Courses) (2012-2017). In the interviews (2016-2017) we included a management representative, conductor of the teaching policies, and four course coordinators, indicated for better consolidating the proposal of integrated training. The data were analyzed from the perspective of content analysis, in which we select the analysis units and identified their content core for the organization of the analytical themes of the study. The data reveal an important attempt to make integral formation effective, although there is a certain mismatch among some conceptions put forward by the literature, the guiding documents and announced by the coordinators.
\end{abstract}

Keywords: Integral Education. Integrated high school education. Federal Institutes. 


\title{
EDUCACSÃ0
}

\section{ENSEÑANZA MEDIA INTEGRADA EN EL IFSULDEMINAS: CAMINOS Y DESCOMPÁS}

\author{
Heloisa Helena Coutinho PEREIRA \\ Luana Costa ALMEIDA
}

\begin{abstract}
Resumen
El artículo objetiva analizar los caminos y conquistas, desafíos y lo que se encuentra fuera del compás en la búsqueda de la implementación de la propuesta de la enseñanza media integrada en el IFSULDEMINAS. Para estos fines, dentro de la perspectiva cualitativa de la encuesta, la investigación tuvo como principales instrumentos de colecta de datos el análisis documental y la entrevista semi estructurada. Documentalmente, utilizamos especialmente los planes de Desarrollo Institucional (2009-2018) y los Proyectos Pedagógicos de los Cursos (2012-2017). En las entrevistas (2016-2017), contemplamos un representante de gestión, conductor de las políticas de enseñanza, cuatro coordinadores del curso, indicados por mejor consolidaren la propuesta de formación integrada. Los datos fueron analizados en la perspectiva del análisis de contenido, en qué seleccionamos las unidades de análisis e identificamos sus núcleos de contenidos para la organización de las temáticas analíticas del estudio. Los datos revelan una tentativa importante de efectividad de la formación integral, aunque haya cierto descompás entre algunas concepciones planteadas por la literatura, por los documentos rectores y anunciados por los coordinadores.
\end{abstract}

Palabras clave: Educación Integral. Enseñanza media integrada. Institutos Federales. 


\section{Introdução}

A Constituição Federal (BRASIL, 1988) estabelece a educação como direito social, com o objetivo de pleno desenvolvimento da pessoa, seu preparo para o exercício da cidadania e sua qualificação para o trabalho - perspectiva reforçada pela Lei de Diretrizes e Bases da Educação, LDB, LLei nº 9.394/1996 (BRASIL, 1996), na qual a Educação Básica está posta como obrigatória dos 4 aos 17 anos, sendo organizada nas etapas: educação infantil, ensino fundamental e ensino médio. Para o ensino médio, estipula-se que, atendida a formação geral do educando, essa etapa poderá prepará-lo para o exercício de profissões técnicas - a educação profissional técnica de nível médio. Sua oferta pode ser efetivada de maneira subsequente, concomitantemente ou desenvolvida de modo integrado à formação geral.

Embora legalmente estabelecida dessa forma, historicamente o ensino médio tem passado por mudanças envolvendo diferentes concepções, as quais se relacionam exatamente à dualidade histórica entre formação profissional técnica e formação geral, de dimensão propedêutica. Especificamente nas últimas décadas, após a LDB de 1996, a educação profissional técnica atrelada ao ensino médio não manteve um mesmo formato de oferta, havendo regulamentações diferentes para essa modalidade e a manifestação explícita da disputa entre diferentes projetos formativos: os ancorados em uma perspectiva de educação integral e aqueles voltados à preparação de mão de obra para o mercado de trabalho.

Logo após a publicação da LDB/1996, o Decreto nº 2.208/1997 regulamentou a separação entre educação profissional e ensino médio (BRASIL, 1997). Esse entendimento representou um retrocesso à ideia defendida pelos estudiosos da área e contida no projeto da LDB proposto pelos educadores, o qual advogava por uma educação integral e unitária (MORAES, 1998; CIAVATTA; RAMOS, 2012; FRIGOTTO; CIAVATTA; RAMOS, 2012).

Mais tarde, em 2004, considerando a entrada de um novo partido político no poder (governo de Luiz Inácio Lula da Silva, iniciado em 2002) e em resposta à reivindicação de grupos de educadores envolvidos com a luta por uma formação integral, que defende para o ensino médio a união entre a formação técnica e a formação geral, o Decreto $n^{\circ}$. 2.208/1997 foi revogado. Nas palavras de Frigotto, Ciavatta e Ramos (2012, p. 26), a revogação do decreto “tornou-se emblemática da disputa e a expressão pontual de uma luta teórica em termos da pertinência políticopedagógica do ensino médio integrado à educação profissional”. O referido decreto foi substituído pelo Decreto $n^{\circ}$. 5.154/2004, o qual restabeleceu a possibilidade de integração entre formação geral 
e profissional (BRASIL, 2004) sem, no entanto, se caracterizar como o avanço esperado pelos educadores mais progressistas (FRIGOTTO; CIAVATTA; RAMOS, 2012).

Em meio a esse movimento, e vinculada a uma concepção integradora do ensino médio com a educação profissional, em 2008 foi instituída a Rede Federal de Educação, Ciência e Tecnologia pela Lei nº. 11.892/2008. Fazendo parte desta Rede, estão os Institutos Federais de Educação, Ciência e Tecnologia, cujo objetivo é ofertar, prioritariamente, o ensino médio na modalidade integrada (BRASIL, 2008).

Fundamentados teoricamente na perspectiva crítica e assumindo o conceito de integração como a busca por uma formação mais ampla, a qual permite relacionar a dimensão propedêutica com a profissional, concordamos com Ramos (2009) que ela deva ser tomada em três sentidos que se complementam: como concepção de formação humana, como forma de relacionar ensino médio e educação profissional e como relação entre parte e totalidade na proposta curricular. O primeiro sentido possibilita uma formação omnilateral ${ }^{3}$ do sujeito, o que implica a integração das dimensões do trabalho, da ciência e da cultura. O trabalho compreendido como realização humana inerente ao ser (sentido ontológico) e como prática econômica (sentido histórico); a ciência, como os conhecimentos produzidos pela humanidade que possibilitam o avanço produtivo; e a cultura, como os valores éticos e estéticos que orientam as normas de conduta (RAMOS, 2009). O segundo sentido estabelece a indissociabilidade entre Educação Profissional e Educação Básica. E o terceiro versa sobre a integração entre conhecimentos gerais e específicos como totalidade, não se tratando de somatório, superposição ou subordinação.

Levando-se em consideração o segundo sentido proposto por Ramos (2009), da indissociabilidade entre Educação Profissional e Educação Básica, temos o ensino médio integrado abordado por alguns autores como uma travessia para uma educação politécnica relacionada com a luta pela superação do dualismo estrutural da sociedade e da educação brasileiras, da divisão de classes e da divisão entre formação para o trabalho manual e para o trabalho intelectual (dentre outros, RAMOS, 2009; FRIGOTTO; CIAVATTA; RAMOS, 2012; MOURA, 2013; MOURA; LIMA FILHO; SILVA, 2015).

A concepção de educação politécnica defende que não se trata de formar um trabalhador adestrado para executar com perfeição determinada tarefa e que se encaixe no mercado de trabalho para desenvolver aquele tipo de habilidade. Trata-se de lhe propiciar um desenvolvimento

\footnotetext{
${ }^{3}$ A formação omnilateral sugere superar o ser humano dividido entre a ação de executar e a de pensar. Trata-se de superar a redução da preparação para o trabalho ao seu sentido restritamente operacional (CIAVATTA, 2012).
} 
multilateral, que abarque todos os ângulos da prática produtiva na medida em que ele domine aqueles princípios que estão na base da organização da produção moderna (SAVIANI, 2003) ${ }^{4}$.

Na perspectiva de Ramos (2009), sobre a identidade do ensino médio e sobre a ampliação das finalidades dessa etapa de ensino, há a necessidade de se observar o trabalho como princípio educativo na construção de um projeto unitário de ensino médio, com vistas ao efetivo desenvolvimento dos sujeitos e emancipação humana. Isso, segundo a autora, não se confunde com o “aprender fazendo” e nem seria sinônimo de “formar para o exercício do trabalho”, já que “tomar o trabalho como princípio educativo equivale a dizer que o ser humano é produtor de sua realidade e, por isto, se apropria dela e pode transformá-la” (RAMOS, 2009, p. 148). Tal princípio é encontrado na Resolução $\mathrm{n}^{\circ}$. 06/2012, que trata das Diretrizes Curriculares Nacionais para a Educação Profissional Técnica de Nível Médio e regula a atuação dos Institutos Federais, estabelecendo como um dos princípios norteadores o "trabalho assumido como princípio educativo, tendo sua integração com a ciência, a tecnologia e a cultura como base da proposta políticopedagógica e do desenvolvimento curricular” (BRASIL, 2012, p. 2).

Fruto de pesquisa qualitativa que se propôs a investigar a organização administrativa e pedagógica dos cursos de ensino médio integrado do Instituto Federal de Educação, Ciência e Tecnologia do Sul de Minas Gerais (IFSULDEMINAS), cotejando-a com a proposição geral do ensino médio integrado constante nos documentos legais e diretrizes que amparam a atuação da instituição, o presente artigo objetiva analisar os aspectos basilares da proposta de formação integral, assim como as ações anunciadas para a consolidação da integração, presentes nos documentos, produzidos no período de 2009 a 2018, e nas falas dos coordenadores de quatro cursos entrevistados entre os anos de 2016 e 2017. Objetiva ainda refletir, em diálogo com teóricos da perspectiva crítica, sobre os caminhos e conquistas, bem como os desafios e descompassos presentes na implementação da proposta de ensino médio integrado nos cursos investigados.

\section{Decisões Metodológicas}

Circunscrita à abordagem qualitativa (LUDKE; ANDRÉ, 2013) e fundamentada na perspectiva crítica, a pesquisa da qual se origina o presente artigo optou, como instrumentos de coleta de dados, pela análise documental e pela entrevista semiestruturada com profissionais do

\footnotetext{
${ }^{4}$ Sobre o conceito de politecnia, Nosella (2007) considera inadequada a expressão educação politécnica no sentido que lhe atribui Saviani, explicitando que nas obras de Marx são usados dois termos, politécnico e tecnológico, mas que, diferentemente de considerá-los sinônimos, devem-se analisar os diferentes sentidos atribuídos aos mesmos, ao que Saviani contesta, explicitando que o termo tecnologia foi definitivamente apropriado pela concepção dominante burguesa, permanecendo a politecnia preservada na tradição socialista, sendo, portanto, preferível a utilização de “educação politécnica” à “educação tecnológica” (SAVIANI, 2003).
} 
IFSULDEMINAS $^{5}$. Especificamente para nosso desenho metodológico, essas técnicas se mostraram pertinentes porque, enquanto a análise documental permitiu o resgate de informações e o mapeamento das diretrizes formativas, as entrevistas semiestruturadas possibilitaram um maior aprofundamento das informações obtidas e dos pontos levantados.

Criado a partir da expansão das redes federais ${ }^{6}$, o IFSULDEMINAS é composto por nove unidades, sendo elas: a Reitoria, localizada em Pouso Alegre; três campi pré-existentes, que eram as antigas escolas agrotécnicas, nas cidades de Inconfidentes, Machado e Muzambinho; três campi novos, localizados nas cidades de Passos, Poços de Caldas e Pouso Alegre; e dois campi avançados, em fase inicial de implantação, nas cidades de Carmo de Minas e Três Corações.

A coleta de dados deu-se em duas etapas:

1) Investigação geral abarcando todo o IFSULDEMINAS, na qual se procedeu a: a) análise de documentos referenciais relativos às diretrizes para a oferta de cursos pelos Institutos Federais, em que priorizamos as diretrizes que amparam a atuação da instituição, especialmente a lei de criação dos Institutos Federais (Lei nº 11.892/2008) e a Resolução $n^{\circ}$. 06/2012, que define as Diretrizes Curriculares Nacionais para a Educação Profissional Técnica de Nível Médio; b) análise de documentos relativos à organização administrativa do ensino médio integrado no IFSULDEMINAS, especialmente os Planos de Desenvolvimento Institucional (2009-2013 e 2014-2018); c) análise de todos os projetos pedagógicos dos 22 cursos ofertados no momento da pesquisa e de suas alterações, elaborados entre os anos de 2012 e 2017; e d) entrevista semiestruturada com um representante da equipe de gestão do instituto, responsável pela condução das políticas macro de ensino.

2) Investigação aprofundada abarcando os cursos indicados pelo gestor entrevistado como aqueles que melhor consolidavam a proposta de formação integrada dentro do IFSULDEMINAS, e que se constituíram de quatro cursos, sendo um pertencente a uma unidade pré-existente (1) e os outros três aos campi avançados $(2,3,4)$. Para cada um deles, procedemos a: a) revisitação dos projetos pedagógicos dos cursos; e b) entrevistas semiestruturadas com os coordenadores.

A opção pela investigação aprofundada nos cursos observados como aqueles que melhor consolidavam a proposta de formação integrada dentro do IFSULDEMINAS deu-se pelo entendimento de que, na impossibilidade de uma investigação que abarcasse todos os 22 cursos, a

\footnotetext{
${ }^{5}$ A investigação foi aprovada pelo Comitê de Ética em Pesquisa. Em respeito ao anonimato dos entrevistados, eles não são nominalmente identificados, sendo, inclusive, utilizado o gênero masculino para todos os sujeitos da pesquisa.

${ }^{6}$ Em 2008, no governo do presidente Luiz Inácio Lula da Silva, foi instituída a Rede Federal de Educação, Ciência e Tecnologia (Lei no . 11.892/2008) e, como parte desta rede, os Institutos Federais de Educação, Ciência e Tecnologia, os quais têm por finalidade ofertar educação profissional e tecnológica, em todos os seus níveis e modalidades, destinando, prioritariamente, $50 \%$ de suas vagas para o ensino médio integrado.
} 
melhor opção seria compreender o processo naqueles que vêm consolidando a proposta em sua vivência cotidiana. Para tanto, buscamos os cursos que melhor promovem a integração na compreensão dos que delineiam as diretrizes gerais, intentando conhecer a percepção dos sujeitos acerca do processo vivenciado, a fim de entender os desafios e potencialidades experienciados.

Após coleta e organização, os dados foram analisados, inspirados na perspectiva da análise de conteúdo (BARDIN, 1977), a qual prevê três fases fundamentais: pré-análise, exploração do material e tratamento dos resultados - inferência e interpretação. Após a leitura dos documentos e entrevistas feitas durante a fase de pré-análise para reconhecimento dos temas tratados, bem como da natureza das informações disponíveis, passamos à seleção das unidades analíticas e, posteriormente, à identificação dos núcleos de conteúdo para a organização das temáticas do estudo $^{7}$, as quais permitiram adentrar a compreensão da integração nos cursos estudados.

\section{Cursos de ensino médio integrado no IFSULDEMINAS: conquistas, desafios, caminhos e descompassos}

Considerando nosso objetivo ao olharmos as diretrizes, tanto nas resoluções gerais externas quanto nos documentos internos, especialmente os planos de desenvolvimento institucional, verificamos o anúncio da defesa de uma formação mais ampla, humanista e integral, evidenciada internamente já na proclamação da missão institucional (IFSULDEMINAS, 2009). De extrema relevância, por configurar o conjunto de princípios que devem nortear as ações do instituto, o Projeto Político Pedagógico Institucional, contido no Plano de Desenvolvimento Institucional do período de 2014-2018, destaca a ideia de uma formação que deve buscar a superação da dicotomia entre formar para o trabalho ou ofertar formação básica, sendo possível notar que a concepção apresentada de educação integradora se volta à busca pela superação da divisão histórica entre formação propedêutica e técnica:

Toda a discussão que foi realizada durante o processo de elaboração deste documento enfatizou a necessidade de que a formação a ser oferecida pelo instituto deve buscar a superação da dicotomia entre a formação para o trabalho e a formação básica do ser humano. [...] uma formação que busque superar a divisão historicamente estabelecida entre o pensar e o agir; entre uma escola que prepara alguns sujeitos para ocuparem os postos de decisão na sociedade e outra que forma mão de obra qualificada para o mercado de trabalho. A educação integradora é, portanto, a educação comprometida com a formação de sujeitos não apenas qualificados para ocuparem postos do mercado de trabalho, mas também conscientes e críticos de sua realidade sócio-político-cultural e, portanto, capazes

\footnotetext{
${ }^{7} \mathrm{O}$ presente artigo não toma as temáticas analíticas separadamente para debate; todavia, elas estão registradas no relatório da pesquisa (PEREIRA, 2017) e consistiram em: “Concepções”, “Ações para integração e articulação”, “Avaliação e acompanhamento” e “Desafios para implementação dos projetos”.
} 
de compreendê-la e de, nela, tomarem decisões e assumirem posicionamentos (IFSULDEMINAS, 2014, p. 162-163, grifos nossos).

O documento revela, ainda, a noção de que para a efetivação dessa formação é necessário assumir o trabalho como princípio educativo, o qual deve ser tomado com outra concepção, distinta da presente no modo de produção capitalista.

No modo de produção capitalista, o significado da palavra trabalho é o de uma relação de troca, ou seja, pelo trabalho o homem oferece a sua força de trabalho em troca de um valor em dinheiro. É o trabalho como trabalho assalariado. A partir deste sentido da palavra trabalho, formar para o trabalho é formar para ocupar uma posição neste mercado de trocas. E uma boa formação, neste contexto, significa formar sujeitos competentes para competirem pelos postos disponíveis neste mercado que, pela lógica do modo de produção capitalista, devem ser sempre em número menor do que o de sujeitos aptos a ocuparem tais postos. Neste tipo de formação, o trabalho é tomado como um contexto a partir do qual se organiza o processo formativo. $\underline{\mathrm{O} \text { outro sentido da palavra trabalho, no qual se fundamenta a }}$ educação integradora, compreende o trabalho de outra maneira. Trabalho significa a forma como o ser humano produz a sua existência. [...] Este é o sentido da palavra trabalho quando pensamos em uma educação integradora. Nela, o trabalho é entendido como princípio educativo e não como contexto (IFSULDEMINAS, 2014, p. 165-166, grifos nossos).

Interessante destaque, porque alinhado com as proposições da literatura, o trabalho como princípio educativo equivale a compreender que o ser humano é produtor de sua realidade e, por isso, pode transformá-la. Rumo à perspectiva de desenvolvimento multilateral, a formação deve abarcar todos os ângulos da prática produtiva, permitindo o domínio dos princípios que estão na base da organização da produção moderna, como bem pontua Saviani (2003).

Dentro dessa perspectiva, a garantia do conhecimento a todos é essencial porque está contida no que se nomeia por “Educação Unitária”. Nas palavras de Ramos (2009, p. 146), “uma educação unitária pressupõe que todos tenham acesso aos conhecimentos, à cultura e às mediações necessárias para trabalhar e para produzir a existência e a riqueza social”. E uma educação dessa natureza, segundo a referida autora, precisa ser politécnica:

Com isto apresentamos os dois pilares conceptuais de uma educação integrada: um tipo de escola que não seja dual, ao contrário, seja unitária, garantindo a todos o direito ao conhecimento; e uma educação politécnica, que possibilita o acesso à cultura, à ciência, ao trabalho, por meio de uma educação básica e profissional. É importante destacar que politecnia não significa o que se poderia sugerir a sua etimologia, a saber, o ensino de muitas técnicas. Politecnia significa uma educação que possibilita a compreensão dos princípios científico-tecnológicos e históricos da produção moderna, de modo a orientar os estudantes à realização de múltiplas escolhas (RAMOS, 2009, p. 146).

Fazendo referência à concepção de educação unitária, politécnica e ligada à formação integral, os projetos pedagógicos dos cursos do IFSULDEMINAS apresentam propostas teórico- 
metodológicas para que a integração almejada seja alcançada. Dentre elas, a busca por um currículo integrado, a interdisciplinaridade e os espaços coletivos como formas de ação.

No Plano de Desenvolvimento Institucional 2009-2013, a concepção de currículo contempla um conjunto integrado de atividades a partir da visão de homem, mundo, sociedade, trabalho, cultura e educação que têm a transversalidade como princípio norteador na formulação e no desenho curricular (IFSULDEMINAS, 2009). Todavia, estariam os projetos pedagógicos dos cursos e a visão de seus coordenadores completamente alinhados a essa perspectiva?

Considerando os quatro cursos investigados em maior profundidade, podemos afirmar que os documentos sinalizam para um entendimento similar ao das diretrizes gerais, mas não necessariamente com a mesma profundidade sugeridas por elas. Já a fala dos coordenadores dos cursos nem sempre compartilham a mesma concepção. Há menção ao trabalho como princípio educativo, à formação mais ampla, à superação da divisão entre formação técnica e geral, portanto, à integração; e, para alcançá-la, a interdisciplinaridade e o trabalho coletivo - porém, por vezes, com entendimento diferenciado daquele anunciado nas diretrizes gerais ou encontrado na literatura que defende a educação integral referenciada na politecnia.

Aspecto abordado na entrevista pelo Gestor, observamos a preocupação em garantir que as concepções presentes no projeto sejam efetivadas no cotidiano das ações e não apenas como intenção, assim como a sua percepção de que há um movimento dos campi para que essa integração ocorra. Todavia, não fica claro se a concepção de integralidade que sustenta sua fala se pauta na interdisciplinaridade e transversalidade das ações, sustentada pela concepção de formação integral tendo o trabalho como princípio educativo, ou se acaba por se configurar apenas como um processo de articulação entre os polos técnico e geral da formação, sem um verdadeiro movimento de integração entre eles, no qual se superaria a fragmentação do processo formativo.

[...] um PPC ele tem que trazer elementos que caracterizem ou que evidenciem essa articulação [a articulação entre ensino médio e formação técnica]. [...] Agora, em termos de ação lá na ponta, lá no campus, nós sabemos que cada campus se organiza pedagogicamente de uma forma, mas de maneira geral, os campi eles fazem ações, reuniões pedagógicas trazendo a pauta, trazendo essa discussão, contando com a equipe pedagógica dos campi, no sentido de construir essa mentalidade, construir esse conceito e estabelecer realmente essa ação como uma ação real e não uma ação ainda de teoria ou apenas que tá dentro de um documento [...] a ideia é essa, que nós, que todos os sujeitos que contribuem na leitura e análise desses PPCs, possamos ter esse olhar (GESTOR, MG, 2016).

Nos projetos pedagógicos dos cursos, há trechos e menções referentes a uma educação integral e até o destaque à busca por ofertar um ensino unitário e politécnico, integrando princípios da ciência, do trabalho e da cultura. No entanto, a compreensão revelada nas entrevistas dos 
coordenadores nem sempre é a mesma dos documentos e nos remete, por vezes, a uma educação articulada, na qual se associa a formação geral à técnica, mas não necessariamente integrada, referenciada pela concepção de educação integral, a qual exigiria uma mudança mais profunda nas concepções que sustentam a ação e, consequentemente, nas formas de organização do trabalho pedagógico, rumo à efetiva superação da dualidade entre formação geral e técnica.

$\mathrm{Na}$ fala em destaque a seguir, o entendimento de politecnia não é o mesmo expresso pela literatura que debate a Educação Integral, em que o trabalho é princípio educativo. Ainda que se refira à dimensão integral e à politecnia, o coordenador traz como elemento analítico, que ultrapassaria o foco nas habilidades técnicas, as soft skills ${ }^{8}$, as quais se voltam mais à preocupação com diferentes habilidades do indivíduo que com uma formação humana comprometida com a superação da dualidade entre trabalho manual e trabalho intelectual.

É justamente desenvolver essas habilidades de poli, que são várias, e desenvolver essas habilidades, não só as habilidades técnicas, mas também as habilidades sociais que nós chamamos, até é um termo em inglês, de soft skills (COORDENADOR 4, MG, 2017).

Outra evidência dessa incompatibilidade entre a literatura, o anunciado nos documentos e a compreensão dos entrevistados sobre a questão pode ser observada no Curso 1 . No projeto pedagógico, declara-se que a matriz curricular deve ser desenvolvida privilegiando-se o trabalho como princípio educativo e pedagógico, buscando-se a integração de conhecimentos gerais e técnico-científicos, com vistas a uma formação integral; porém, o coordenador traz essa dimensão de forma mais restrita.

Em entrevista, o coordenador 1 trata a questão como se o trabalho como princípio educativo e a integração de conhecimentos gerais e técnico-científicos se voltassem simplesmente a uma formação mais humanística, direcionada para a constituição de um sujeito capaz de enxergar o próximo “como ser vivo, como irmão”, não formado apenas com a visão técnica. Aspecto que não deve ser desmerecido por sinalizar a intencionalidade de ultrapassar a fragmentação na formação dos estudantes, mas que não se constitui como representativo da essência do que seria a formação integral no viés defendido pela literatura.

A integração, para mim, é um conjunto de ações que vai desde a elaboração do projeto pedagógico até a formação final, porque a integração vai permitir realmente a pessoa se tornar mais humanista, a pessoa realmente enxergar o próximo como ser vivo, como irmão. A integração ela vai provocar uma mudança de comportamento, de forma que ele passe a ter uma melhor postura na vida, como

\footnotetext{
${ }^{8}$ Soft skills é um termo em inglês comumente utilizado na área de recursos humanos e empresarial para fazer referência às habilidades comportamentais e competências subjetivas que ultrapassam as competências técnicas. Segundo Andrade (2016), elas compreendem um conjunto de habilidades sociais, interpessoais, qualidades da pessoa e atributos de carreira que envolvem aptidões mentais, emocionais e sociais.
} 
cidadão e que ele venha responder à expectativa de toda a sociedade de promover o desenvolvimento da sociedade, porque quando eu trabalho simplesmente por competência é uma questão, eu não enxergo ninguém, eu sou competente, eu tenho que apertar parafuso, eu sei apertar parafuso. Mas isso é muito pouco para uma pessoa, é muito pouco para um ser humano. Ele tem de ter uma visão mais globalizada, uma visão mais até humanizada do que simplesmente ter uma visão técnica, o tecnicismo em si que aquilo tem que ser e não pode se mudar de forma alguma (COORDENADOR 1, MG, 2017, grifos nossos).

Ainda em relação à formação integral, vale destacar que o Coordenador 2 apresenta uma visão mais próxima ao defendido nos documentos e princípios teóricos, quando assume a integração entre formação técnica e geral como caminho de superação da dicotomia que separa a dimensão prática da dimensão teórica. Ao falar do domínio dos conhecimentos necessários para a vida e para o trabalho, ele menciona a necessidade de uma formação que favoreça sua integração.

Eu vejo essa formação, como o próprio nome diz, mais humanística, porque é aquilo que eu disse, não estamos fazendo robozinho que tem que saber isso pra poder fazer um vestibular ou tem que saber aquilo para poder trabalhar, ele vai saber o conteúdo que vai unir a prática à teoria e ao mesmo tempo ele vai saber onde vai aplicar isso. Então, para a vida dele vai ser muito melhor [...] Acho que o que a gente pode favorecer neles, nesse sentido, é isso, mostrar essa integração e essa aplicabilidade e isso favorece o aprendizado que ele vai levar para o resto da vida (COORDENADOR 2, MG, 2017, grifos nossos).

Em relação às ações assumidas para a consolidação da integração nos cursos pesquisados, um aspecto que se mostrou marcante foi a valorização de uma construção coletiva do trabalho. Presente nas diversas falas dos entrevistados e destacada pelo Coordenador 2, assume-se o trabalho coletivo como caminho fundamental na busca pela efetivação da integração no curso.

Existem reuniões pedagógicas e reuniões de curso, ao fim dessas reuniões, pelo menos uma vez por mês, os professores das disciplinas dos integrados se reúnem e traçam metas do que integrar, de como está sendo a integração e do que está funcionando e o que precisa melhorar. O PPC também prevê isso, que existam essas reuniões periódicas, justamente para as áreas se conversarem [...], então é uma das formas de que isso ocorra e é efetiva. São essas reuniões periódicas entre os professores das áreas integradas para que isso ocorra e outra também é a parte pedagógica que sempre está nos apoiando, porque querendo ou não é o projeto da escola é o projeto de todo mundo, todo mundo sentou ali, idealizou e teve um pedacinho de cada um ali dentro, então cada um que idealizou essa etapa de integração, acaba cobrando "Porque isso não está acontecendo, porque que isso tem que acontecer”, então isso é seguido. [...] É um trabalho aí árduo de toda a equipe todo mundo se esforçou muito [...] todos os núcleos pedagógico, técnico e propedêutico, se não, não nascia, porque se eu vejo a possibilidade naquela disciplina, da gente integrar e da gente unir esses contextos, só que se o outro professor não vê a mesma coisa o trabalho não vai acontecer depois, então antes, os dois sentarem, discutirem esse vai, esse não vai, isso a gente consegue resolver junto, isso não dá, realmente eu tenho que fazer separado. Se não tiver essa conversa não flui (COORDENADOR 2, MG, 2017, grifos nossos). 
Destaque importante foi dado à dimensão da interdisciplinaridade, manifestada na menção à construção do currículo integrado e trazida como forma de abordagem dos conteúdos nos projetos dos quatro cursos. Aspecto também presente na literatura da área como basilar na efetivação de propostas integradoras, ela é vista como meio importante para a consolidação dessas propostas.

Ramos (2011), dentre outros, expõe que um currículo integrado convergente com a formação do sujeito em múltiplas dimensões tem a interdisciplinaridade como método. A autora explicita que não se trata de somente contextualizar conhecimentos científicos no trabalho e na cidadania, mas que trabalho, ciência e cultura são dimensões da vida humana que devem ser integradas ao e no currículo, o que exige uma abordagem interdisciplinar dos conteúdos para se consolidar.

Não se trata simplesmente de se contextualizar conhecimentos científicos no trabalho e na cidadania - relações designadas como contextos -; aliás, nem o trabalho é delimitado como contexto, nem este forma uma dualidade com a cidadania. Trabalho, ciência e cultura são dimensões da vida humana que devem ser integradas ao currículo e no currículo, tendo o trabalho como princípio educativo (RAMOS, 2011, p. 776).

Com a intenção de trabalhar a dimensão interdisciplinar nos cursos, além da busca pelo diálogo com professores de outras áreas e de acordos coletivos, destaca-se a criação nos cursos 2, 3 e 4 do núcleo articulador e dos projetos integradores como ações que demonstram potencialidade para efetivar a integração dos conteúdos. Conforme podemos observar nos trechos a seguir, a interação entre professores de diferentes áreas é fundamental, e os espaços curriculares denominados "núcleo articulador" e "projetos integradores" funcionam como exigência desse diálogo e trabalho conjunto em relação aos conteúdos desenvolvidos em determinado semestre.

Como podemos notar na fala do coordenador 4, o eixo articulador no curso que ele coordena funciona como meio de diálogo entre as áreas, de modo que algumas disciplinas são escolhidas para mediarem a integração entre a área geral e a técnica, absorvendo obrigatoriamente professores da área técnica e da área propedêutica

Então nós temos no PPC o eixo articulador que faz isso, as disciplinas, têm as disciplinas do primeiro ano, do segundo e do terceiro que elas fazem parte do eixo articulador. Essas disciplinas têm que conversar com a área técnica, então eles têm matemática, por exemplo, está lá no eixo articulador, então ela trabalha junto com as disciplinas do professor, por exemplo, dando linguagem de programação, lógica de programação... Então elas têm que conversar de alguma maneira (COORDENADOR 4, MG, 2017).

Como outra estratégia de organização em direção à integração, o coordenador 2 explica que se busca integrar a área técnica à geral não somente por meio do eixo articulador, mas construindo os chamados projetos integradores, os quais articulam professores das diferentes áreas. 
Nós temos a prática, por exemplo, dos projetos integradores. Os projetos integradores, o próprio nome diz, são para integrar várias disciplinas e, como já previsto no PPC, também ele deve integrar obrigatoriamente professores da área técnica e da área propedêutica, área de formação geral, e isso condiz justamente com as disciplinas integradas, mas não vai só ao encontro delas [...] então são formas de não só trocar ideias, trocar conceitos, mas interagir também, não só propedêutica e área técnica, mas entre áreas distintas também e integrar (COORDENADOR 2, MG, 2017).

Esses espaços curriculares exigem uma forma de trabalho conjunto que estimula, e para o qual é imprescindível, a noção de interdisciplinaridade, a qual, mais que diálogo entre as áreas, favorece um trabalho verdadeiramente articulado em que se toma o mesmo objeto a partir de múltiplas determinações. Como exemplificado por Ramos (2012), ao citar como objeto de estudo a construção de uma usina hidrelétrica, a análise de uma dada realidade requer uma abordagem em múltiplas perspectivas.

Por exemplo, a construção de uma usina hidrelétrica numa determinada região, problematizada na perspectiva tecnológica evidenciaria teorias, conceitos e procedimentos técnico-científicos predominantemente da Física. Mas, se problematizado na perspectiva ambiental, por exemplo, evidenciar-se-iam questões, teorias e conceitos da Biologia e da Geografia. Mas toda questão ambiental é também econômica e política, portanto, ao ser tratada nessas perspectivas, serão evidenciados conceitos das Ciências Sociais. Enfim, nenhuma perspectiva em si esgotaria a totalidade do fenômeno. Por isto, o currículo integrado requer a problematização dos fenômenos em múltiplas perspectivas, mas também uma abordagem metodológica que permita apreender suas determinações fundamentais (RAMOS, 2012, p. 123).

Frigotto et al. (2014, p. 16) explicita que, “do ponto de vista epistemológico, o desafio de um trabalho na forma curricular integrada, interdisciplinar, não como justaposição, mas como construção coletiva, é conflituoso, é construção histórica”, daí a importância do desenvolvimento de formas de trabalho coletivo que abram espaço para esse movimento - aspecto presente na fala dos coordenadores entrevistados, quando mencionam formas e espaços nos cursos para a consolidação do trabalho, citando, dentre outros, as reuniões, a elaboração coletiva das propostas e a efetivação de trocas e projetos comuns como meios de efetivação desse trabalho coletivo.

O Coordenador 3 destaca a importância da construção coletiva do projeto pedagógico do curso. Quando há envolvimento dos professores, acaba-se por favorecer o comprometimento com a efetivação do projeto.

No momento de criação do projeto pedagógico, todos professores participaram e foi um trabalho árduo, todos nós nos envolvemos, a parte pedagógica foi fundamental para nesse auxílio e a gente conseguiu realmente agregar isso a um projeto pedagógico, a gente não conseguia ver isso em outros locais. Nós buscamos informações “como a gente vai fazer isso?” Mas aqui a gente queria realmente uma coisa inovadora e aparentemente nós conseguimos, a gente fica feliz com isso (COORDENADOR 3, MG, 2017). 
Já o Coordenador 1 destaca que, sem diálogo, não é possível construir a integração no curso. Ele enfatiza que o debate e a construção de entendimentos comuns são essenciais para o processo.

Não existe ensino integrado e interdisciplinaridade sem conversa, sem discussão: esquece! Quem acha que vai trabalhar e vai promover, desenvolver a concepção de ensino integrado, interdisciplinaridade sem discussão e sem conversa e sem um conhecer o outro: esquece! Porque não vai ser por comunicação de trocas de e-mail, de trocas de falas em redes sociais que isso vai resolver (COORDENADOR 1, MG, 2017).

Um aspecto apontado por todos os entrevistados e que se mostra relevante na construção da integração, observado como desdobramento do trabalho coletivo, é o apoio de toda a equipe, inclusive gestores, para a efetivação do projeto. Para Araujo e Frigotto (2015), há várias possibilidades de arranjos pedagógicos e curriculares que favorecem as práticas pedagógicas orientadas pela ideia de integração; e a escolha por um tipo de arranjo depende de inúmeras variáveis, como as condições de formação, a maturidade profissional do professor, o perfil da turma e o tempo disponível, porém sendo decisivo o compromisso docente com as ideias de formação integrada e de transformação social.

Uma das evidências observadas na análise dos dados foi a ideia de que o compromisso do coletivo com a efetivação dos projetos exigiria práticas de avaliação e acompanhamento dos processos. Nos cursos pesquisados, evidenciaram-se movimentos de reflexão para repensar as ações.

Os coordenadores entrevistados demonstraram preocupação em avaliar a condução dos projetos e, a partir do acompanhamento das ações e dos resultados obtidos, realinhar as ações. Ponto positivo, dada a necessidade e a importância da autorreflexão, já que a autoavaliação deve ser um processo em que os atores busquem construir conhecimentos sobre sua realidade, investigando como as ações em andamento estão se consolidando em busca da melhoria da qualidade educativa (ALMEIDA, 2016), sendo processos essenciais por possibilitarem, recorrentemente, a reflexão sobre o andamento e execução dos projetos em vias da consolidação de concepções e aprimoramento de ações.

A partir das entrevistas, foi possível perceber que, mesmo buscando a integração, há questões de difícil superação, como a diferença entre os campi na condução das políticas de integração vislumbradas pelo projeto do instituto e especificidades que dificultam a construção de um trabalho mais articulado. Dentre outras particularidades, observamos a disputa entre professores de diferentes áreas como empecilho para a efetivação do trabalho integrado nas disciplinas, mais evidente no curso 1 que nos demais, e a indisponibilidade do quantitativo necessário de professores formados nas áreas específicas das disciplinas, evidenciado como problema pelo coordenador 4. 
Em relação à indisponibilidade do quantitativo necessário de professores formados nas áreas específicas das disciplinas, essa questão coloca-se como desafio à integração pela sobrecarga de trabalho que acarreta, impossibilitando novas formas de organização. Como destaca o coordenador 4, o trabalho conjunto e integrado fica ainda mais difícil de ser efetivado sem o quantitativo adequado de profissionais.

Eu acho que hoje, hoje a gente tem uma equipe aqui e uma equipe ainda em formação, então eu acredito que nós precisamos de mais professores, isso é uma coisa que nós estamos precisando, nós temos, eu acho que agora a gente já vai conseguir professores de suas áreas específicas, porque nós temos situaccões de professor que assumiu disciplinas, mas que não é muito da área dele, nós temos 0 caso da matemática, da física, que eu acho que isso é uma coisa que quando a gente resolver esse problema, vai ser melhor ainda. Nós temos casos também de professores que assumiram muitas disciplinas porque o professor saiu de licença, veio professor substituto da área de humanas, o professor é muito bom, mas com uma sobrecarga de disciplinas, isso acaba que pode deixar um pouco cansativo pros alunos, então na verdade nós precisamos de mais professores. Isso é uma coisa que vai fazer toda a diferença quando a gente tiver mais professores que possam ajudar, porque a equipe é pequena, acaba que às vezes a gente fica um pouco sobrecarregado, então eu acho que quando acontecer isso da gente ter professores cada um atuando mesmo na sua área, eu acho que essa integração vai ser melhor ainda para que ele seja realmente o curso integrado e que a gente consiga preparar os alunos de fato, para o mercado de trabalho e para essas opções que eles têm depois de continuar os estudos, de fazer uma faculdade, de fazer um curso superior (COORDENADOR 4, MG, 2017, grifos nossos).

Importante ressaltar, todavia, que, mesmo sendo necessário um número suficiente de professores e com formação específica, há também a necessidade de que esses docentes tenham um perfil voltado a concepções que lhes permitam trabalhar de forma integrada. Para Pacheco, Pereira e Domingos Sobrinho (2010), pautados nas concepções e diretrizes postas aos Institutos Federais, esse modelo curricular integrado exige mudanças no perfil profissional docente inserido na rede, para que ele seja capaz de lidar com o conhecimento de forma integrada e desenvolva um trabalho reflexivo e criativo, permitindo a construção da autonomia dos educandos.

Em relação à diferença entre os campi na execução das políticas e projetos pedagógicos, uma hipótese a ser investigada em estudos posteriores é se as características históricas de cada unidade seriam fator importante na abertura do corpo docente à efetivação do projeto de integração. Isso porque, na entrevista com o coordenador do campus pré-existente, ele menciona a consolidação de certa cultura tecnicista e resistência à quebra de paradigmas naquela unidade. Para ele, a efetivação de novas formas de organização exigiria a abertura para outras formas de pensar a formação.

Ainda que as evidências sejam insuficientes, sendo necessário o aprofundamento da análise envolvendo outros sujeitos, como professores e estudantes, a diferença entre as unidades se 
manifesta em nossos dados na percepção de dois de nossos entrevistados. Para o coordenador 1, os campi pré-existentes avançaram menos na consolidação dos projetos de integração porque, dentre outros aspectos, possuem uma cultura institucional já arraigada.

Os novos campi eles avançaram mais do que os campi antigos. [...] Tanto é, que a integração mesmo, a interdisciplinaridade... [...] a gente sabe que está sendo muito mais efetiva do que nos três iniciais, até porque não existia um curso, então os cursos já foram montados, trabalhados dentro dessa concepção e os próprios docentes não eram viciados em ministrar aulas isoladamente. Muitos começaram a carreira aqui no próprio instituto, então já começaram de uma forma mais adequada (COORDENADOR 1, MG, 2017).

Esse aspecto foi corroborado pelo coordenador 4, ao mencionar que mesmo professores com desejo de ações diferenciadas não têm espaço nos campi pré-existentes em decorrência dessa cultura institucional mencionada pelo coordenador 1, a que chamou de "vícios".

Diferente desses campi maiores, por exemplo, os maiores que já tinham vícios, já tinham costume, às vezes a pessoa entra com ideias, com vontade de fazer diferente e não consegue[...] (COORDENADOR 4, MG, 2017).

Possivelmente relacionada a essa questão, a disputa entre os professores da área técnica e geral, mencionada pelo coordenador 1, parece relacionada a uma cultura institucional que percebe de forma distinta a importância das disciplinas no curso, assim como favorece a condução individual dos conteúdos em detrimento de um trabalho mais coletivo. A forma tradicional de fazer e estar no curso, assim como os paradigmas já consolidados, dificultam a organização mais integrada na formação. Como pode ser observado a partir da fala do coordenador 1, acaba sendo um processo de convencimento.

Como te falei, no início foi muito difícil porque os professores do núcleo básico achavam que eles trabalhariam para nós do núcleo técnico. E a gente foi discutindo, discutindo, eles foram deixando as pedras de lado, largando as pedras porque eles passaram a entender que o curso é único. Não é que eles deviam trabalhar, assumir nossa responsabilidade da parte técnica, mas trabalhar em conjunto para poder potencializar as nossas forças, para potencializar os nossos conhecimentos (COORDENADOR 1, MG, 2017).

Essa percepção da necessidade de convencimento na unidade pré-existente como diferente das novas faz sentido na medida em que os campi novos, por estarem abertos às mudanças e novos paradigmas, se mostram mais propícios à construção de propostas diferentes que favoreceriam o processo de integração: novos professores, sem os hábitos de uma tradição de dualidade e fragmentação, estariam mais abertos a novas formas de organização do trabalho pedagógico.

Emerge como hipótese, portanto, que as unidades mais antigas, pela tradição que possuem e pela forma estável com que sempre conduziram as ações, estão menos propensas a implementar mudanças. Já as unidades novas, que se iniciaram com uma mentalidade diferente, sem resquícios 
de uma outra prática, podem trilhar novas formas de conduzir os processos, o que facilitaria a efetivação da integração.

Considerando os percalços e desafios da implementação do ensino médio integrado no IFSULDEMINAS, não bastassem as dificuldades internas a serem enfrentadas, observa-se a aprovação da reforma do ensino médio, sancionada pelo então presidente da República Michel Temer, em fevereiro de 2017, pela Lei $\mathrm{n}^{\circ}$. 13.145/2017 (BRASIL, 2017), como elemento complexificador da consolidação da questão. Suas delimitações suscitam dúvida acerca da possibilidade de continuidade da proposta organizativa assumida pelos Institutos Federais.

Contextualizada no debate sobre a Medida Provisória $\mathrm{n}^{\circ}$. 746/2016, que antecedeu a homologação da referida reforma, em sua entrevista, o Gestor mencionou dúvidas acerca das consequências dessa política para a proposta pedagógica assumida no IFSULDEMINAS. Frente ao estabelecimento de itinerários formativos para o ensino médio e uma concepção de formação que se distancia, em muito, da integradora, o gestor evidenciou insegurança e incerteza quanto à possibilidade de continuidade das práticas integradoras que vêm sendo buscadas e realizadas nos cursos.

A gente acredita nessa proposta, a gente acredita que isso faz a diferença na vida dos estudantes, embora agora a gente se sinta assim, há um sentimento de, no mínimo, ameaçados com tudo isso que tá acontecendo, politicamente falando, e até agora a gente não tem nada muito definido para nós, enquanto instituições federais... E ninguém fala claramente como será ou o que será do nosso fazer...e... dá uma tristeza muito grande de pensar que possam fazer ações no sentido de desintegrar isso tudo, haja vista que já está acontecendo aí fora... Então a gente tá vendo isso com muita tristeza, profunda tristeza, como algo de um retrocesso absurdo, um retrocesso... Nossa, não consigo nem mensurar... (GESTOR, MG, 2016).

Tal insegurança não é infundada, pois a proposta assumida pela reforma se distancia daquela defendida na perspectiva da Educação Integral. Como bem pontuou Ferretti (2016) em entrevista concedida à Associação Nacional de Pós-Graduação e Pesquisa em Educação (ANPEd), a perspectiva da segmentação do currículo por meio das “opções formativas” coloca em questão a formação integral de caráter omnilateral pela segmentação curricular que estabelece.

Em síntese, constatamos que a busca pela integração nos cursos analisados é um processo em constante construção, que, por isso mesmo, revela potencialidades e limitações a serem consideradas na continuidade da caminhada. Nas palavras de Frigotto et al. (2014, p. 16), “do ponto de vista epistemológico, o desafio de um trabalho na forma curricular integrada, interdisciplinar, não como justaposição, mas como construção coletiva, é conflituoso, é construção histórica”, o que respalda a sensação de nossos entrevistados quanto a ser um processo que não apenas se desenrola no tempo, como traz potencialidades e desafios a serem analisados e enfrentados coletivamente: 
Hoje já melhorou muito, ainda não está aquilo que a gente espera, nós tivemos uma reunião ainda essa terça-feira, a gente conseguiu já com a coordenadoria geral de ensino de termos reuniões a cada 15 dias, duas horas. [...] já é um avanço porque a gente não tinha nenhum horário... tempo para fazer essas reuniões pra trabalhar as questões da integração: como está, como está sendo desenvolvido, onde a gente pode melhorar, como a gente vai poder realmente criar as avaliações interdisciplinares... Como a grande parte nunca trabalhou interdisciplinaridade, então também é um conhecimento novo, não é fácil de nós iniciarmos nesse primeiro bimestre, principalmente, e já iniciarmos com tudo, então está caminhando aos poucos também para não errar, pra evitar o mínimo de erro possível, porque se nós errarmos, o reflexo direto é na qualificação do nosso estudante. Então a gente está indo aos poucos também com segurança, pra evitar erros que possam prejudicar o conhecimento dos estudantes (COORDENADOR 1, MG, 2017).

Nessa perspectiva, consideramos que os caminhos percorridos na busca pela integração nos cursos pesquisados em maior profundidade têm demonstrado aspectos produtivos, com condutas que vêm demonstrando o quanto há ações e compromisso em construir, na prática e coletivamente, os conceitos que estão aventados como princípios pelos documentos norteadores. Todavia, como parte de todo processo vivo, evidenciam-se também os desafios e descompassos existentes na caminhada, necessitando ser aprimorada, especialmente, a busca pela consolidação das concepções que alicerçam o processo para que os profissionais se unam em torno de um mesmo norte. É sabido, porém, que a busca pela efetiva integração é um processo de construção constante e, possivelmente, não passível de finalização, sendo cada passo dado rumo à consolidação da educação integral razão de orgulho e motivação para continuar a caminhada.

\section{Considerações Finais}

Este trabalho buscou apresentar parte dos resultados encontrados na pesquisa que se propôs a analisar a organização administrativa e pedagógica dos cursos de ensino médio integrado do IFSULDEMINAS. Baseados em dados empíricos e bibliográficos, buscamos debater o sentido e o processo de integração no ensino médio integrado do IFSULDEMINAS. O foco foi analisar os aspectos basilares da proposta de formação integral presentes nos documentos consultados, conforme descrito no item metodológico, e na fala de coordenadores de quatro cursos, assim como as ações anunciadas para a consolidação da integração, de forma a refletirmos sobre os caminhos e conquistas, bem como os desafios e descompassos presentes na implementação da proposta de ensino médio integrado nos cursos investigados. Ao olharmos para os documentos norteadores, de forma geral, percebemos que a proposição institucional se alinha com a construção de uma educação que procura englobar trabalho, ciência e cultura em um currículo integrado e de perspectiva interdisciplinar. 
A análise documental dos projetos pedagógicos possibilitou-nos concluir que esses documentos apresentam concepção voltada à educação integral e explicitam a metodologia que tem sido usada para a efetivação da integração, sendo essa principalmente a busca pela interdisciplinaridade e o trabalho conjunto de professores na integração de conteúdos. Nesse sentido, os espaços curriculares reservados aos "projetos integradores” e "núcleo articulador" se destacaram como práticas promissoras na busca pela superação da dualidade entre formação técnica e formação geral, propedêutica. Ao olhar para os depoimentos dos coordenadores, observamos um trabalho comprometido com a efetivação da integração, porém nem sempre alinhado conceitualmente com o defendido pelos documentos norteadores ou expressos na literatura.

Identificamos no percurso da pesquisa que a busca pela integração é um processo que, mesmo tendo avançado nos cursos estudados, possui limites e barreiras a serem enfrentadas. Destaca-se, em primeiro lugar, a necessidade de alinhamento conceitual; as diferenças que ocorrem de uma unidade para outra, possivelmente ligadas à preexistência das unidades e consequente tradição em relação a algumas concepções e formas de organização do trabalho pedagógico; e também as dificuldades relacionadas ao próprio curso, dentre as quais se evidencia a disputa de espaço entre os professores dos núcleos técnico e geral.

Entendemos que os cursos investigados, na busca por uma educação integral, trilham um percurso de conquistas e, também, de desafios. Um caminho possível para o enfrentamento dos desafios, especialmente relacionados à cultura institucional arraigada, parece ser o investimento em processos de formação permanente com vistas ao debate da educação integral e politécnica, o qual contribuiria para a construção de uma outra cultura entre os professores, a partir de processos mais coletivos e partilhados de reflexão.

Amparados pela literatura da área (FERRETTI, 2016; FERREIRA, 2017; FERREIRA; SILVA, 2017; MOTTA; FRIGOTTO, 2017), fica claro que o debate sobre a formação integral é atual e bastante latente do ponto de vista ideológico. Assim como, historicamente, na oferta do ensino médio no Brasil, há uma clássica divisão entre a formação geral, ampla, e a formação exclusiva para o mercado de trabalho, técnica, essa dualidade recoloca-se com intensidade a partir da reforma do ensino médio sancionada em 2017. Dessa forma, o que ainda prevalece é a luta dos educadores mais progressistas por uma educação integral em detrimento da visão fragmentada voltada para o mercado de trabalho. 


\section{Referências}

ALMEIDA, L.C. Autoavaliação do Mestrado em Educação da Univás: caminho, achados e possibilidade. Argumentos Pró-Educação, Pouso Alegre, v. 1, n.3, p. 500-515, set./dez. 2016. Disponível em: http://ojs.univas.edu.br/index.php/argumentosproeducacao/issue/view/12/23. Acesso em: 30 ago. 2020.

ANDRADE, C. S. L. A influência das soft skills na atuação do gestor: a percepção dos profissionais de gestão de pessoas. 2016. 125f. Dissertação (Mestrado) - Escola Brasileira de Administração Pública e de Empresas, Rio de Janeiro, 2016. Disponível em: http://bibliotecadigital.fgv.br/dspace/handle/10438/17711. Acesso em: 12 out. 2017.

ARAUJO, R.; FRIGOTTO, G. Práticas pedagógicas e ensino integrado. Revista Educação em Questão, Natal, v. 52, n.38, p. 61-80, maio-ago. $2015 . \quad$ Disponível em: https://periodicos.ufrn.br/educacaoemquestao/article/viewFile/7956/5723. Acesso em: 09 jun. 2017.

BARDIN, L. Análise de Conteúdo. Lisboa: Edições 70, 1977.

BRASIL. [Constituição (1988)] Constituição da República Federativa do Brasil de 1988. Brasília, DF. Disponível em: http://www.planalto.gov.br/ccivil_03/constituicao/ConstituicaoCompilado.htm. Acesso em: 07 maio 2017.

BRASIL. Decreto $n^{\circ}$. 2.208, de 17 de abril de 1997. Regulamenta o $\S 2^{\circ}$. do art. 36 e os arts. 39 a 42 da Lei $n^{\circ}$. 9.394, de 20 de dezembro de 1996, que estabelece as diretrizes e bases da educação nacional. Disponível em: http://www.planalto.gov.br/ccivil_03/decreto/D2208.htm. Acesso em: 07 maio 2017.

BRASIL. Decreto $n^{\circ}$. 5.154, de 23 de julho de 2004. Regulamenta o §2 $2^{\circ}$ do art. 36 e os arts. 39 a 41 da Lei $n^{\circ}$. 9.394, de 20 de dezembro de 1996, que estabelece as diretrizes e bases da educação nacional, e dá outras providências. Disponível em: http://www.planalto.gov.br/ccivil_03/_ato20042006/2004/decreto/d5154.htm. Acesso em: 07 maio 2017.

BRASIL. Lei $n^{\circ}$. 9.394, de 20 de dezembro de 1996. Estabelece as Diretrizes e Bases da Educação Nacional (LDB). Disponível em: www.planalto.gov.br/ccivil_03/leis/L9394.htm. Acesso em: 07 maio 2017.

BRASIL. Lei $n^{\circ}$. 11.892, de 29 de dezembro de 2008. Institui a Rede Federal de Educação Profissional, Científica e Tecnológica, cria os Institutos Federais de Educação, Ciência e Tecnologia e dá outras providências. Disponível em: http://www.planalto.gov.br/ccivil_03/_ato20072010/2008/lei/l11892.htm. Acesso em: 07 maio 2017.

BRASIL. Lei $n^{\circ}$. 13.145, de 16 de fevereiro de 2017. Altera as Leis $n{ }^{\circ} .9 .394$, de 20 de dezembro de 1996, que estabelece as diretrizes e bases da educação nacional, e 11.494, de 20 de junho 2007, que regulamenta o Fundo de Manutenção e Desenvolvimento da Educação Básica e de Valorização dos Profissionais da Educação, a Consolidação das Leis do Trabalho - CLT, aprovada pelo Decreto-Lei $\mathrm{n}^{\circ}$. 5.452, de $1^{\circ}$ de maio de 1943, e o Decreto-Lei $n^{\circ} .236$, de 28 de fevereiro de 1967; revoga a Lei $\mathrm{n}^{\circ}$.11.161, de 5 de agosto de 2005; e institui a Política de Fomento à Implementação de Escolas de Ensino Médio em Tempo Integral. Disponível em: http://www.planalto.gov.br/ccivil_03/_ato20152018/2017/lei/l13415.htm. Acesso em: 30 ago. 2020.

BRASIL. Resolução CNE/CEB $n^{\circ}$. 6, de 20 de setembro de 2012. Define Diretrizes Curriculares Nacionais para a Educação Profissional Técnica de Nível Médio. Disponível em: http://portal.mec.gov.br/index.php?option=com_docman\&view=download\&alias=11663-rceb006-1 2-pdf\&category_slug=setembro-2012-pdf\&Itemid=30192. Acesso em: 10 jun. 2017. 
CIAVATTA, M. A formação integrada: a escola e o trabalho como lugares de memória e de identidade. In: FRIGOTTO, Gaudêncio; CIAVATTA, Maria; RAMOS, Marise (Orgs.). Ensino médio integrado: concepção e contradições. 3. ed. São Paulo: Cortez, 2012. p.83-106

CIAVATTA, M; RAMOS, M. A “era das diretrizes”: a disputa pelo projeto de educação dos mais pobres. Revista Brasileira de Educação, Rio de Janeiro, v. 17, n.49, p. 11-37, jan./abr. 2012. Disponível em: http://www.scielo.br/pdf/rbedu/v17n49/a01v17n49.pdf . Acesso em: 07 mar. 2017.

FERREIRA, E. B. A contrarreforma do ensino médio no contexto da nova ordem e progresso. Educação \& Sociedade, Campinas, v.38, n. 139, p. 293-308, abr./jun. 2017. Disponível em: http://www.scielo.br/pdf/es/v38n139/1678-4626-es-38-139-00293.pdf. Acesso em: 08 jul. 2017.

FERREIRA, E. B.; SILVA, M. Centralidade do ensino médio no contexto da nova "ordem e progresso”. Educação \& Sociedade, Campinas, v.38, n. 139, p. 287-292, abr./jun. 2017. Disponível em: http://www.scielo.br/pdf/es/v38n139/1678-4626-es-38-139-00287.pdf. Acesso em: 08 jul. 2017.

FERRETTI, C. J. Entrevista com Celso Ferretti - Ensino médio - Série “conquistas em risco”. 2016. [Entrevista cedida a] Associação Nacional de Pós-Graduação e Pesquisa em Educação. 2016. Disponível em: http://www.anped.org.br/news/entrevista-com-celso-ferretti-ensino-medio-serieconquistas-em-risco. Acesso em: 18 ago. 2017.

FRIGOTTO, G.; CIAVATTA, M.; RAMOS, M. A gênese do Decreto no 5.154/2004: um debate no contexto controverso da democracia restrita. In: FRIGOTTO, G.; CIAVATTA, M.; RAMOS, M.(Org.). Ensino médio integrado: concepção e contradições. 3. ed. São Paulo: Cortez, 2012. p. 21-56.

FRIGOTTO, G. et al. Produção de conhecimentos sobre Ensino Médio Integrado: dimensões epistemológicas e político-pedagógicas. In: COLÓQUIO PRODUÇÃO DE CONHECIMENTOS DE ENSINO MÉDIO INTEGRADO: DIMENSÕES EPISTEMOLÓGICAS E POLÍTICOPEDAGÓGICAS, 2010. Rio de janeiro. Anais [...] Rio de Janeiro: EPSJV/Fiocruz, 2014. Disponível em: http://www.epsjv.fiocruz.br/sites/default/files/l232.pdf. Acesso em: 08 jun. 2017.

INSTITUTO FEDERAL DE EDUCAÇÃO, CIÊNCIA E TECNOLOGIA SUL DE MINAS GERAIS (IFSULDEMINAS). Plano de Desenvolvimento Institucional. Pouso Alegre, 2009. Disponível

em:

https://portal.ifsuldeminas.edu.br/images/PDFs/Institucional/Plano_de_Desenvolvimento_Insitucional.pdf. Acesso em: 06 jun. 2017.

INSTITUTO FEDERAL DE EDUCAÇÃO, CIÊNCIA E TECNOLOGIA SUL DE MINAS GERAIS (IFSULDEMINAS). Plano de Desenvolvimento Institucional 2014-2018. Pouso Alegre, 2014.

Disponível

em:

http://portal.ifsuldeminas.edu.br/images/PDFs/acoes_e_programas_/PDI2014-

2018Ifsuldeminas.pdf. Acesso em: 25 jun. 2017.

LUDKE, M.; ANDRE, M.E.D.A. A Pesquisa em educação: abordagens qualitativas. 2. ed. Rio de Janeiro: E.P.U., 2013.

MORAES, C. S.V. A reforma do ensino médio e a educação profissional. Trabalho e Educação, Belo Horizonte, n.3, p. 107-117, jan./jul.1998. Disponível em: https://periodicos.ufmg.br/index.php/trabedu/article/view/8921. Acesso em: 26 mar. 2017.

MOTTA, V. C.; FRIGOTTO, G. Por que urgência da reforma do ensino médio? Medida provisória $n^{0}$ 746/2016 (Lei nº. 13.415/2017). Educação \& Sociedade, Campinas, v.38, n. 139, p. 355-372, abr./jun. 2017. Disponível em: http://www.scielo.br/pdf/es/v38n139/1678-4626-es-38-13900355.pdf. Acesso em: 08 jul. 2017. 
MOURA, D. H. Ensino médio integrado: subsunção aos interesses do capital ou travessia para a formação humana integral? Educação e Pesquisa, São Paulo, v. 39, n.3, p. 705-720, jul./set. 2013. Disponível em: http://www.scielo.br/pdf/ep/v39n3/10.pdf . Acesso em: 05 maio 2017.

MOURA, D. H.; LIMA FILHO, D. L.; SILVA, M. R. Politecnia e formação integrada: confrontos conceituais, projetos políticos e contradições históricas da educação brasileira. Revista Brasileira da Educação, v. 20, n.63, p. 1057-1080, out./dez. 2015. Disponível em: http://www.scielo.br/pdf/rbedu/v20n63/en_1413-2478-rbedu-20-63-1057.pdf. Acesso em: 05 maio 2017.

NOSELLA, P. Trabalho e perspectivas de formação dos trabalhadores: para além da formação politécnica. Revista Brasileira de Educação, v. 12, n 34, p. 137-181, jan./abr. 2007. Disponível em: http://www.scielo.br/pdf/rbedu/v12n34/a11v1234.pdf. Acesso em: 05 maio 2017.

PACHECO, E. M.; PEREIRA, L. A. C.; DOMINGOS SOBRINHO, M. Institutos Federais de Educação, Ciência e Tecnologia: limites e possibilidades. Linhas Críticas, Brasília, DF, v. 16, n. 30, p. 71-88, jan./jun. 2010. Disponível em: http://periodicos.unb.br/index.php/linhascriticas/article/view/3568. Acesso em: 05 jun. 2017.

PEREIRA, H.H.C. Ensino médio integrado: uma análise do IFSULDEMINAS. 2017. $142 \mathrm{f}$. Dissertação (Mestrado) - Universidade do Vale do Sapucaí, Pouso Alegre, 2017. Disponível em: http://www.univas.edu.br/me/docs/dissertacoes2/76.pdf. Acesso em: 29 ago. 2020.

RAMOS, M. Concepção do ensino médio integrado. In: ARAUJO, R. M. L.; TEODORO, E. G.; Porto, Adriana Maria Nazaré de Souza (Org.). Ensino médio integrado no Pará como política pública. Belém: Seduc-PA, 2009. p. 144-182.

RAMOS, M. Possibilidades e desafios na organização do currículo integrado. In: FRIGOTTO, G.; CIAVATTA, M.; RAMOS, M. (Orgs.). Ensino médio integrado: concepção e contradições. 3. ed. São Paulo: Cortez, 2012. p. 107-128.

RAMOS, M. N. O currículo para o ensino médio em suas diferentes modalidades: concepções, propostas e problemas. Educação \& Sociedade, Campinas, v. 32, n 116, p. 771-788, jul./set. 2011. Disponível em: http://www.scielo.br/pdf/es/v32n116/a09v32n116.pdf. Acesso em: 23 mar. 2017.

SAVIANI, D. O choque teórico da politecnia. Trabalho, Educação e Saúde, Rio de Janeiro, v. 1, n 1, p. 131-152, 2003. Disponível em: http://www.scielo.br/pdf/tes/v1n1/10.pdf. Acesso em: 12 abr. 2017.

Recebido em: 09/10/2019

Aprovado em: 18/08/2020 